\title{
Electrochemical Determination of Acetylsalicylic acid in Human Urine Samples Based on Poly (diallyldimethylammonium chloride) Functionalized Reduced Graphene Oxide Sheets
}

\author{
Hang Zhu \\ Putian Univeristy, Dong Zhen West Road No. 450, Putian City, Fujian Province, 351100, P.R.China; \\ E-mail: hangzhupt@gmail.com
}

doi: $10.20964 / 110395$

Received: 21 January 2016 / Accepted: 23 February 2016 / Published: 1 April 2016

In this contribution, a poly (diallyldimethylammonium chloride) functionalized reduced graphene oxide (PDDA-RGO) was synthesized via a simple one-pot hydrothermal approach using urea as reducing agent. The synthesized PDDA-RGO was carefully characterized via various techniques including scanning electron microscopy, transmission electron microscopy, X-ray powder diffraction, Raman spectroscopy and Fourier transform infrared spectroscopy. The synthesized PDDA-RGO was then used as an electrode surface modifier for electrochemically determination of acetylsalicylic acid. Cyclic voltammetry and differential pulse voltammetry were used as determination techniques. Various determination parameters were optimized as well. Moreover, the application of the proposed sensor was successfully applied for acetylsalicylic acid determination in human urine samples.

Keywords: Graphene; PDDA; Electrochemical; Acetylsalicylic acid; Sensor

\section{$\underline{\text { FULL TEXT }}$}

(C) 2016 The Authors. Published by ESG (www.electrochemsci.org). This article is an open access article distributed under the terms and conditions of the Creative Commons Attribution license (http://creativecommons.org/licenses/by/4.0/). 